\title{
CDISC SDTM Diabetes Therapy Terminology
}

National Cancer Institute

\section{Source}

National Cancer Institute. CDISC SDTM Diabetes Therapy Terminology. NCI Thesaurus.

Code C101857.

Terminology associated with the diabetes therapy codelist of the Clinical Data

Interchange Standards Consortium (CDISC) Study Data T abulation Model (SDT M). 